\title{
Red clover extract exerts antidiabetic and hypolipidemic effects in $\mathrm{db} / \mathrm{db}$ mice
}

\author{
LONGXIN QIU ${ }^{1,2^{*}}$, TONG CHEN $^{1,2^{*}}$, FOJIN ZHONG $^{1}$, YAMIN HONG $^{1}$, LIMEI CHEN $^{1}$ and HONG YE ${ }^{1}$ \\ ${ }^{1}$ School of Life Sciences and ${ }^{2}$ Fujian Key Laboratory of Preventive Veterinary Medicine and Biotechnology, \\ Longyan University, Longyan 364000, P.R. China
}

Received May 15, 2012; Accepted August 2, 2012

DOI: $10.3892 /$ etm.2012.658

\begin{abstract}
To investigate the effects of red clover extract on the blood glucose and lipid levels of type 2 diabetic $\mathrm{db} / \mathrm{db}$ mice, male $\mathrm{db} / \mathrm{db}$ mice were treated with this extract for a period of 5 weeks. The red clover extract had a significant effect on lowering the blood glucose levels of $\mathrm{db} / \mathrm{db}$ mice. The serum triglyceride, serum total cholesterol, liver triglyceride and liver cholesterol levels for diabetic mice receiving red clover extract were significantly lower compared to those of the untreated diabetic mice. The mRNA expression of two target genes transcriptionally regulated by peroxisome proliferator-activated receptor (PPAR) $\gamma$ was determined by quantitative real-time RT-PCR, and red clover extract was observed to significantly upregulate hepatic glucokinase and CD36 expression. Four target genes transcriptionally regulated by PPAR $\alpha$ were also assayed, and red clover extract was observed to significantly downregulate hepatic apolipoprotein C3 expression whereas it had no significant effect on apolipoprotein A5, acetyl CoA oxidase and carnitine palmitoyl transferase-1 expression. In addition, hepatic mRNA expression of fatty acid synthase was also observed to be downregulated by red clover extract treatment. Thus, we conclude that red clover extract significantly improves the glucose and lipid homeostasis in $\mathrm{db} / \mathrm{db}$ diabetic mice and that these effects are achieved at least in part by activating hepatic PPAR $\alpha / \gamma$ and by inhibiting hepatic fatty acid synthase.
\end{abstract}

\section{Introduction}

Plant extracts containing isoflavones have been the focus of numerous studies during the last decade due to their protective effects against menopausal symptoms and a variety of

Correspondence to: Dr Longxin Qiu, School of Life Sciences, Longyan University, Longyan 364000, P.R. China

E-mail: qlongxin@tom.com

${ }^{*}$ Contributed equally

Key words: red clover extract, type 2 diabetes mellitus, lipid homeostasis, peroxisome proliferator-activated receptors, fatty acid synthase disorders, including cardiovascular disease, cancer, hyperlipidemia and osteoporosis $(1,2)$. In addition, the potential of dietary isoflavones in the prevention of diabetes mellitus has attracted increased attention among the public and in the medical community in recent years $(2,3)$. Soy isoflavones were reported to be beneficial for correcting hyperglycemia and improving lipid profiles in streptozotocin (STZ)-induced diabetic rats (4) and obese Zucker rats (5). The intervention studies of patients with type 2 diabetes have reported favorable effects of soy isoflavones on glycated hemoglobin or insulin resistance $(6,7)$. However, other studies have reported that soy isoflavone intake does not exert beneficial effects on patients with type 2 diabetes $(8,9)$. Therefore, the effect of isoflavones on diabetes remains inconclusive and more investigations need to be performed using isoflavones from plants other than soy.

While soy isoflavones are the most studied isoflavones used in studies on diabetes, few data are available for red clover (Trifolium pratense) isoflavones. Isoflavones from red clover differ from soy; the principal isoflavones in red clover are biochanin A, formononetin, genistein and daidzein while those in soy consist solely of genistein and daidzein. We previously reported that red clover extract ameliorated dyslipidemia in STZ-induced type 1 diabetic mice, but did not correct hyperglycemia (10). However, whether red clover extract exerts antidiabetic and hypolipidemic effects in type 2 diabetic animals remains unclear.

Among the mechanisms whereby isoflavones ameliorate hyperglycemia and dyslipidemia, one may be the activation of peroxisome-proliferator activated receptors (PPARs), nuclear receptors that participate in cellular lipid homeostasis and insulin action (11). PPAR $\gamma$ ligands, like glitazones, are clinically used to treat type 2 diabetes as insulin-sensitizing drugs and PPAR $\alpha$ ligands, like fibrates, are used to manage elevated blood lipid levels and type 2 diabetes as hypolipidemic agents. Isoflavones from red clover were demonstrated to be a potent PPAR $\alpha / \gamma$ dual agonist, and among those isoflavones, biochanin A is a more potent PPAR $\alpha / \gamma$ agonist than its metabolite genistein, and formononetin is also more potent than daidzein (12). Thus, further study on the antidiabetic effects and molecular mechanisms of red clover extract in type 2 diabetes animal models needs to be conducted. In the present study, using $\mathrm{db} / \mathrm{db}$ mice as a model of type 2 diabetes, we aimed to determine whether red clover extract exerts antidiabetic and hypolipidemic effects in type 2 diabetic animals. We 
Table I. Primer sequences used for amplification of mRNA by real-time PCR.

\begin{tabular}{lll}
\hline Gene & & \multicolumn{1}{c}{ Sequences } \\
\hline PPAR $\alpha$ & Forward: & 5'-AAGAGGGCTGAGCGTAGGT-3' \\
& Reverse: & 5'-GGCCGGTTAAGACCAGACT-3' \\
APOC3 & Forward: & 5'-GTGTTGCAGATGTGCCTGTT-3' \\
& Reverse: & 5'-GGAGGGGTGAAGACATGAGA-3' \\
APOA5 & Forward: & 5'-GAACGCTTGGTGACTGGAAT-3' \\
& Reverse: & 5'-TCGCCTTACGTGTGAGTTTG-3' \\
ACO & Forward: & 5'-CCACATATGACCCCAAGACC-3' \\
& Reverse: & 5'-AGGCATGTAACCCGTAGCAC-3' \\
CPT-1 & Forward: & 5'-GTCAAGCCAGACGAAGAACA-3' \\
& Reverse: & 5'-CGAGAAGACCTTGACCATAG-3' \\
FAS & Forward: & 5'-TGCTCCCAGCTGCAGGC-3' \\
& Reverse: & 5'-GCCCGGTAGCTCTGGGTGTA-3' \\
SREBP-1c & Forward: & 5'-ATCGGCGCGGAAGCTGTCGGGGTAGCGTC-3' \\
& Reverse: & 5'-ACTGTCTTGGTTGTTGATGAGCTGGAGCAT-3' \\
PPAR $\gamma$ & Forward: & 5'-CAAACCCTTACCACGGTTGA-3' \\
& Reverse: & 5'-CCATTGGGTCAGCTCTTGTGA-3' \\
Glucokinase & Forward: & 5'-TGAGATGGATGTGGTGGCAA-3' \\
& Reverse: & 5'-CATGCCGACCTCACATTGG-3' \\
CD36 & Forward: & 5'-TGTTCCTCGCCATGAAATGA-3' \\
& Reverse: & 5'-GCTAGGCAGCATGGAACTTGA-3' \\
& Forward: & 5'-CGACGACCCATTCGAACGTCT-3' \\
& Reverse: & 5'-CTCTCCGGAATCGAACCCTGA-3' \\
& & \\
& & \\
& & \\
& & \\
& &
\end{tabular}

also investigated whether the PPAR $\alpha / \gamma$ agonist mechanisms of red clover isoflavones are involved in the hyperglycemia and dyslipidemia improvement.

\section{Materials and methods}

Materials. Red clover extract was purchased from a common Chinese pharmacy and was standardized to $10 \%$ isoflavones (consisting of $10.2 \%$ formononetin, $9.6 \%$ biochanin A, $0.32 \%$ genistein and $0.08 \%$ daidzein).

Animal experiments. All experiments were conducted according to protocols and guidelines approved by Longyan University Institutional Animal Care and Use Committee. $\mathrm{db} / \mathrm{db}\left(\right.$ BKS.Cg-m/Lepr $\left.{ }^{\mathrm{db}} / \mathrm{J}\right)$ mice were obtained from the Jackson Laboratory (Bar Harbor, ME, USA). All animals were maintained on a standard laboratory diet under a 12/12-h light/dark schedule. Male db/db mice, 7-8 weeks of age, were randomly divided into 3 experimental groups (each containing 6 animals): $\mathrm{db} / \mathrm{db}$ mice, $\mathrm{db} / \mathrm{db}+10 \mathrm{mg} / \mathrm{kg} /$ day red clover extract, $\mathrm{db} / \mathrm{db}+50 \mathrm{mg} / \mathrm{kg} / \mathrm{day}$ red clover extract. Red clover extract was administered orally in $0.5 \%$ sodium carboxymethyl cellulose (CMC) suspension and continued for 35 days.

Determination of blood glucose and serum lipids. The blood glucose level was measured periodically throughout the exper- imental period using a glucometer (OneTouch Ultra; LifeScan, Inc., Milpitas, CA, USA). At the end of the red clover extract treatment, the mice were sacrificed and blood was collected by orbital sinus puncture. Serum triglycerides (TG) and total cholesterol (TC) were measured using commercial kits (Jiancheng, Nanjing, China).

Liver lipid analyses. Liver lipid was extracted by chloroform/methanol. Briefly, pulverized liver was homogenized in PBS, then extracted with chloroform/methanol (2:1), dried overnight and resuspended in a solution of $60 \%$ butanol $40 \%$ Triton X-114/methanol (2:1). Liver total TG and cholesterol levels were measured using colorimetric assays (Jiancheng).

Quantitative analyses of the $m R N A$ expression by real-time $P C R$. Total RNA was isolated from tissues using the TRIzol reagent (Invitrogen, Carlsbad, CA, USA) according to the manufacturer's instructions. Complementary DNA (cDNA) was synthesized from hepatic mRNA using RevertAid ${ }^{\mathrm{TM}}$ First Strand cDNA Synthesis kits (Fermentas, Vilnius, Lithuania). Hepatic acetyl CoA oxidase (ACO), carnitine palmitoyl transferase-1 (CPT-1), apolipoprotein A5 (APOA5), APOC3, sterol regulatory element binding protein $1 \mathrm{c}(\mathrm{SREBP}-1 \mathrm{c})$ and fatty acid synthase (FAS) mRNA were analyzed with the specific primers listed in Table I. Real-time polymerase chain reactions were assayed using the FastStart Universal SYBR-Green 
Master (Rox; Roche Applied Science, Mannheim, Germany). Each Ct value was normalized to $18 \mathrm{~S}$ rRNA.

Statistical analysis. Quantitative data are expressed as mean \pm SEM. The Student's t-test was used for pairwise comparisons and one-way ANOVA with Newman-Keuls multiple comparison test for multigroup analyses. $\mathrm{P}<0.05$ was considered to indicate a statistically significant result.

\section{Results}

Red clover extract attenuates hyperglycemia in $d b / d b$ mice by activating PPAR $\gamma$. To investigate the effect of red clover extract on the development of diabetes, we treated two groups of mice with red clover extract at the doses of 10 or $50 \mathrm{mg} / \mathrm{kg} /$ day, respectively, for 5 weeks. Fig. 1 shows the effect of red clover extract treatment on blood glucose level in $\mathrm{db} / \mathrm{db}$ diabetic mice. After 4 weeks treatment with red clover extract, the blood glucose levels of the 10 and $50 \mathrm{mg} / \mathrm{kg} / \mathrm{day}$ red clover extract-treated $\mathrm{db} / \mathrm{db}$ mice were $18.5 \pm 2.4$ and $16.3 \pm 2.3 \mathrm{mmol} / \mathrm{l}$, respectively, compared with $27.3 \pm 1.3 \mathrm{mmol} / \mathrm{l}$ in the control untreated $\mathrm{db} / \mathrm{db}$ mice $(\mathrm{P}<0.05$ and $\mathrm{P}<0.01$, respectively). In addition, after 5 weeks of treatment with red clover extract, the blood glucose levels of the 10 and $50 \mathrm{mg} / \mathrm{kg} / \mathrm{day}$ red clover extract-treated $\mathrm{db} / \mathrm{db}$ mice were $17.2 \pm 2.9$ and $12.7 \pm 1.0 \mathrm{mmol} / \mathrm{l}$, respectively, compared with $26.5 \pm 1.3 \mathrm{mmol} / \mathrm{l}$ in the control untreated $\mathrm{db} / \mathrm{db}$ mice $(\mathrm{P}<0.05$ and $\mathrm{P}<0.001$, respectively). Our data suggest that red clover extract treatment attenuates hyperglycemia in type 2 diabetic animals.

Glucokinase, a key enzyme involved in the regulation of glucose metabolism, and CD36, a scavenger receptor involved in hepatic fatty acid uptake, are two hepatic genes regulated by PPAR $\gamma(13,14)$. To determine whether red clover extract attenuates hyperglycemia in diabetic mice by activating PPAR $\gamma$, we analyzed the mRNA expression of PPAR $\gamma$, glucokinase and CD36. After 5 weeks of red clover extract treatment, expression of glucokinase and CD36 was significantly upregulated (3.4-fold, $\mathrm{P}<0.01$ and 2.1 -fold, $\mathrm{P}<0.05)$ in $50 \mathrm{mg} / \mathrm{kg} /$ day red clover extract-treated diabetic mice (Fig. 2).

Red clover extract regulates lipid homeostasis in db/db mice by activating hepatic PPAR $\alpha$ and inhibiting hepatic FAS. To determine the effects of red clover extract on the overall lipid metabolism in the diabetic animals, we examined the levels of serum TG and TC in $\mathrm{db} / \mathrm{db}$ mice with or without red clover extract treatment for a period of 5 weeks. Red clover extract-treated $\mathrm{db} / \mathrm{db}$ mice had significantly lower blood $\mathrm{TG}$ $(99.9 \pm 17.4 \mathrm{mg} / \mathrm{dl}$ for $\mathrm{db} / \mathrm{db}+10 \mathrm{mg} / \mathrm{kg}$ red clover extract vs. $167.5 \pm 11.0 \mathrm{mg} / \mathrm{dl}$ for $\mathrm{db} / \mathrm{db}, \mathrm{P}<0.01 ; 85.2 \pm 6.0 \mathrm{mg} / \mathrm{dl}$ for $\mathrm{db} / \mathrm{db}+50 \mathrm{mg} / \mathrm{kg}$ red clover extract vs. $167.5 \pm 11.0 \mathrm{mg} / \mathrm{dl}$ for $\mathrm{db} / \mathrm{db}, \mathrm{P}<0.001$ ) in comparison with the untreated $\mathrm{db} / \mathrm{db}$ mice (Fig. 3A). In addition, both 10 and $50 \mathrm{mg} / \mathrm{kg} /$ day of red clover extract treatment caused significant decreases in serum TC levels in $\mathrm{db} / \mathrm{db}$ mice $(132.7 \pm 13.3 \mathrm{mg} / \mathrm{dl}$ for $\mathrm{db} / \mathrm{db}$ $+10 \mathrm{mg} / \mathrm{kg}$ red clover extract vs. $191.1 \pm 12.8 \mathrm{mg} / \mathrm{dl}$ for $\mathrm{db} / \mathrm{db}$, $\mathrm{P}<0.05 ; 142.2 \pm 14.7 \mathrm{mg} / \mathrm{dl}$ for $\mathrm{db} / \mathrm{db}+50 \mathrm{mg} / \mathrm{kg}$ red clover extract vs. $191.1 \pm 12.8 \mathrm{mg} / \mathrm{dl}$ for $\mathrm{db} / \mathrm{db}, \mathrm{P}<0.05$; Fig. 3B). However, the TC lowering effect was not dose-dependent.

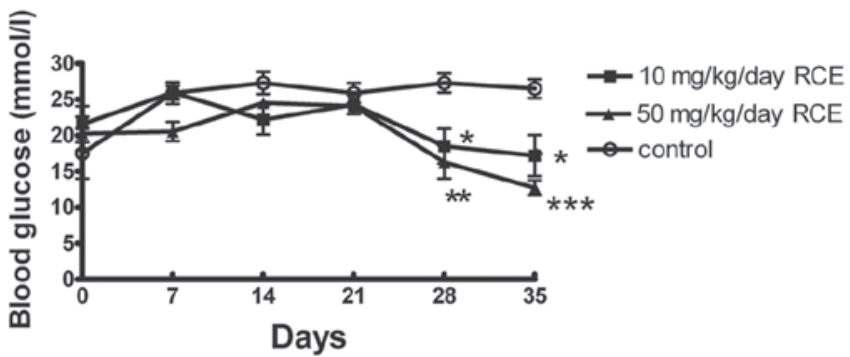

Figure 1. Effect of red clover extract treatment on blood glucose level of $\mathrm{db} / \mathrm{db}$ diabetic mice. Mouse groups used were $\mathrm{db} / \mathrm{db}, 10 \mathrm{mg} / \mathrm{kg}$ red clover extract (RCE)-treated $\mathrm{db} / \mathrm{db}$ and $50 \mathrm{mg} / \mathrm{kg}$ RCE-treated $\mathrm{db} / \mathrm{db}$ (n=6/group). The data are expressed as mean \pm SEM, ${ }^{*} \mathrm{P}<0.05 ;{ }^{* *} \mathrm{P}<0.01 ;{ }^{* * *} \mathrm{P}<0.001$.

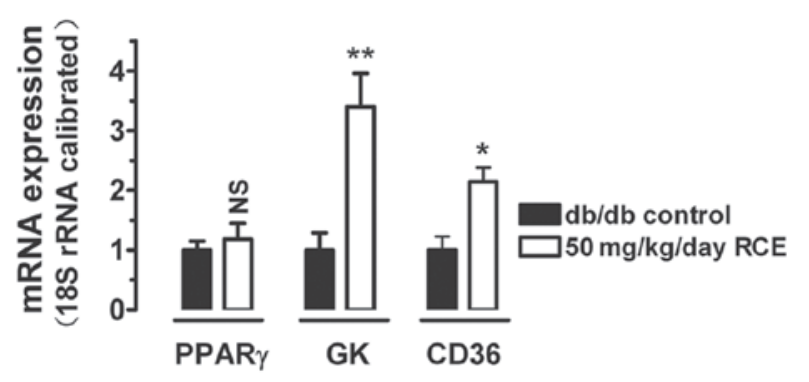

Figure 2. Hepatic mRNA expression of PPAR $\gamma$, glucokinase and CD36 after $\mathrm{RCE}$ treatment in $\mathrm{db} / \mathrm{db}$ mice. mRNA expression was analyzed by quantitative real-time RT-PCR. Values are expressed as mean \pm SEM. ${ }^{~} \mathrm{P}<0.05$; ${ }^{* *} \mathrm{P}<0.01 . \mathrm{n}=4$ for each group. GK, glucokinase; RCE, red clover extract.

Notably, no apparent difference in food consumption was observed in all the experimental groups (data not shown).

In addition, we investigated the effects of red clover extract on the liver lipid levels in $\mathrm{db} / \mathrm{db}$ mice. As shown in Fig. $3 \mathrm{C}$ and $\mathrm{D}, 10 \mathrm{mg} / \mathrm{kg} / \mathrm{day}$ and $50 \mathrm{mg} / \mathrm{kg} /$ day red clover extract treatment in $\mathrm{db} / \mathrm{db}$ mice significantly reduced hepatic TG by $\sim 18.3$ and $24.1 \%$, respectively, $(19.1 \pm 1.0 \mathrm{mg} / \mathrm{g}$ tissue for $\mathrm{db} / \mathrm{db}+10 \mathrm{mg} / \mathrm{kg}$ red clover extract vs. $23.3 \pm 0.5 \mathrm{mg} / \mathrm{g}$ tissue for $\mathrm{db} / \mathrm{db}, \mathrm{P}<0.05 ; 17.7 \pm 1.6 \mathrm{mg} / \mathrm{g}$ tissue for $\mathrm{db} / \mathrm{db}+$ $50 \mathrm{mg} / \mathrm{kg}$ red clover extract vs. $23.3 \pm 0.5 \mathrm{mg} / \mathrm{g}$ tissue for $\mathrm{db} / \mathrm{db}, \mathrm{P}<0.01)$ and reduced hepatic cholesterol by $\sim 40.5$ and $51.5 \%$, respectively $(3.6 \pm 0.9 \mathrm{mg} / \mathrm{g}$ tissue for $\mathrm{db} / \mathrm{db}+10 \mathrm{mg} / \mathrm{kg}$ red clover extract vs. $6.1 \pm 1.0 \mathrm{mg} / \mathrm{g}$ tissue for $\mathrm{db} / \mathrm{db}, \mathrm{P}>0.05$; $2.9 \pm 0.3 \mathrm{mg} / \mathrm{g}$ tissue for $\mathrm{db} / \mathrm{db}+50 \mathrm{mg} / \mathrm{kg}$ red clover extract vs. $6.1 \pm 1.0 \mathrm{mg} / \mathrm{g}$ tissue for $\mathrm{db} / \mathrm{db}, \mathrm{P}<0.05$ ).

Isoflavones like biochanin A and formononetin are reported to be potent agonists of PPAR $\alpha(12,15,16)$. To determine the effects of red clover extract treatment on certain target genes of PPAR $\alpha$ in the liver, we analyzed hepatic ACO, CPT-1, APOC 3 and APOA5 mRNA expression in $\mathrm{db} / \mathrm{db}$ diabetic mice. After 5 weeks of red clover extract treatment, APOC3, a protein capable of inhibiting TG hydrolysis by lipoprotein lipase (LPL) was downregulated by $54.8 \%(\mathrm{P}<0.05)$ in the $50 \mathrm{mg} / \mathrm{kg}$ red clover extract-treated diabetic mice (Fig. 4A). In contrast to $\mathrm{APOC} 3$, only slight and insignificant alterations were observed for APOA5, ACO and CPT-1.

The effect of red clover extract on fatty acid synthesis was also investigated. After 5 weeks of red clover extract treatment, the hepatic mRNA expression of FAS was significantly 
A

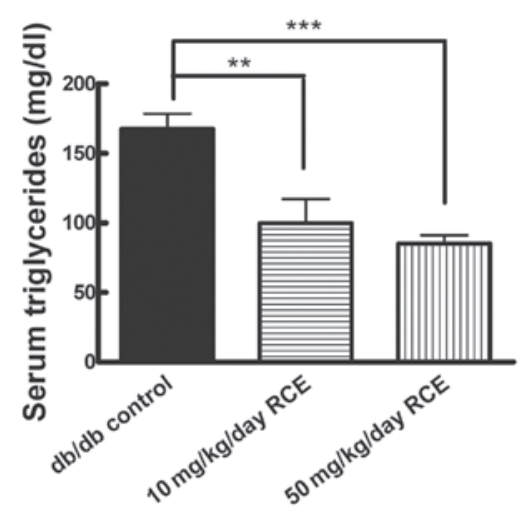

C

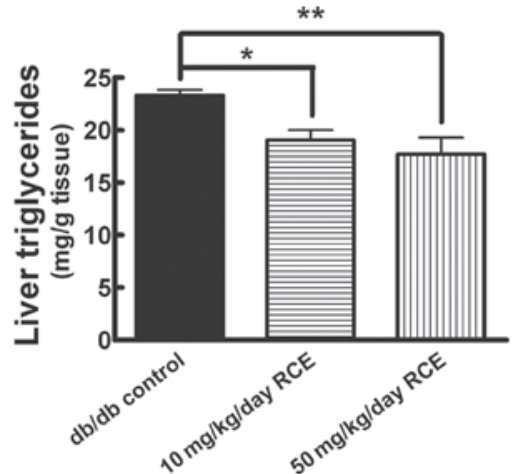

B

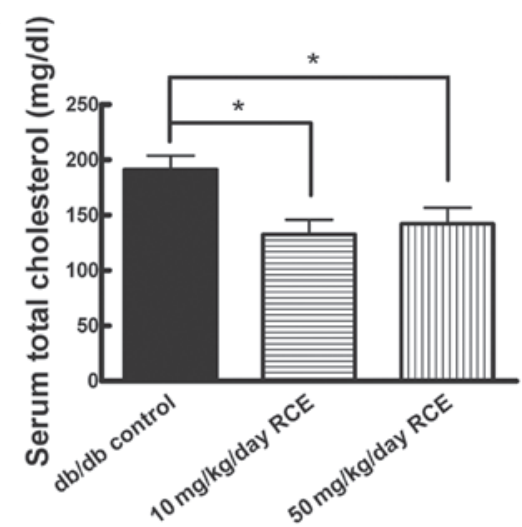

D

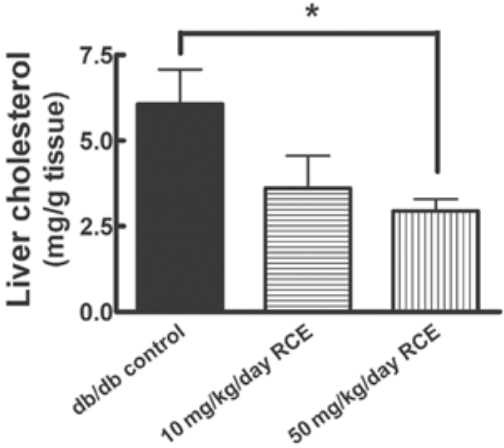

Figure 3. Effect of red clover extract treatment on serum and liver lipid profiles in db/db mice. Red clover extract (RCE) treatment significantly decreased the (A) serum triglyceride, (B) serum total cholesterol, (C) liver triglyceride and (D) liver cholesterol levels in $\mathrm{db} / \mathrm{db}$ mice. $\mathrm{n}=6 \mathrm{for}$ each group. Data are expressed as mean \pm SEM. ${ }^{*} \mathrm{P}<0.05 ;{ }^{* *} \mathrm{P}<0.01 ;{ }^{* * *} \mathrm{P}<0.001$.

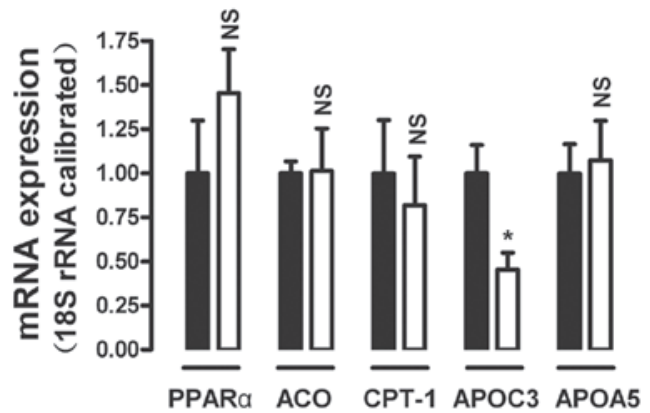

B

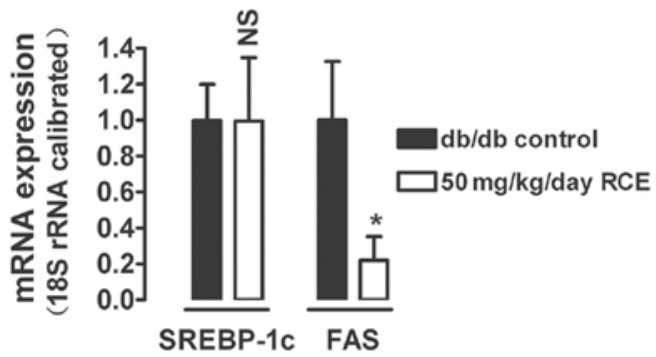

Figure 4. Hepatic mRNA expression of genes involved in lipid metabolism after RCE treatment in db/db mice. mRNA expression was analyzed by quantitative real-time RT-PCR. Values are expressed as mean \pm SEM. ${ }^{*} \mathrm{P}<0.05$. $\mathrm{n}=4$ for each group. RCE, red clover extract.

downregulated by $78 \%(\mathrm{P}<0.05)$ in the $50 \mathrm{mg} / \mathrm{kg}$ red clover extract-treated diabetic mice (Fig. 4B). However, mRNA expression of SREBP-1c, a protein that regulates FAS expression, was not changed by red clover extract treatment.

\section{Discussion}

In vitro studies have demonstrated that biochanin $\mathrm{A}$, formononetin and genistein, three of the isoflavones from red clover are effective PPAR $\gamma$ agonists $(12,15,16)$. In this study, we demonstrated that red clover extract treatment resulted in activation of known PPAR $\gamma$-regulated genes in the liver in vivo. The activation of PPAR $\gamma$ improves insulin sensitivity, which maintains the blood glucose homeostasis (17). The glucokinase activation resulting from PPAR $\gamma$ activation also maintains the blood glucose homeostasis since glucokinase is a glucose sensor (14). Therefore, the PPAR $\gamma$ agonist property of red clover extract could partially explain its hypoglycemic mechanism. However, certain studies reported that purified isoflavones were ineffective at activating PPAR $\gamma$ whereas soy protein isolate was effective in vivo (18), which suggests that nonisoflavone phytochemicals or their metabolites are responsible for the activation of PPAR $\gamma$. Therefore, whether biochanin A and formononetin or other nonisoflavone phytochemicals from red clover extract activate hepatic PPAR $\gamma$ in diabetic mice remains to be investigated.

The hypoglycemic effects of isoflavones remain controversial. Certain studies have reported that isoflavones are beneficial for correcting hyperglycemia in STZ-induced diabetic rats (4), obese Zucker rats (5) and in patients with type 2 diabetes $(6,7)$. Certain other studies have reported that isoflavone intake does not exert anti-hyperglycemic effects on STZ-induced diabetic mice (10) and type 2 diabetes patients $(8,9)$. In addition, there are certain debates upon the 
hypolipidemic effect of red clover isoflavones under various disease conditions. Several studies reported the effect of red clover extract on improving lipid profile $(10,19-22)$ whereas other studies did not identify an effect $(23,24)$. Our current data is consistent with certain previous studies (10) suggesting that red clover extract ameliorates dyslipidemia in diabetic animals. Furthermore, we demonstrated that red clover extract downregulated the hepatic mRNA expression of APOC3, a target gene transcriptionally regulated by PPAR $\alpha$. PPAR $\alpha$ is an important metabolic nuclear receptor that regulates lipid metabolism through direct transcriptional control of genes involved in peroxisomal and mitochondrial $\beta$-oxidation pathways, fatty acid uptake, and TG catabolism (25). Hepatic activation of PPAR $\alpha$ by its agonists, such as WY-14643, decreases blood TG levels by upregulating the expression of LPL and APOA5 and downregulating APOC3 $(26,27)$. In the present study, however, the mRNA expression of APOA5, ACO and CPT-1, three other PPAR $\alpha$-regulated genes, was not altered by red clover extract treatment. The diversity of PPAR $\alpha$ target gene expression following PPAR $\alpha$ activation was also reported in certain other studies $(10,28)$, yet the underlying molecular mechanism remains unclear.

FAS is the multifunctional protein that plays a central role in de novo fatty acid synthesis and in the long-term regulation of lipogenesis (29). The promoter region of FAS contains binding sites for the transcription factor called SREBP-1c (30). In the present study, we demonstrated that the hepatic mRNA expression of FAS in diabetic db/db mice was significantly downregulated by red clover extract treatment. However, SREBP-1c mRNA expression was not altered simultaneously. SREBP is synthesized as inactive precursors and the NH2 terminal domain of SREBP must be cleaved in a 2-step proteolytic process by site-1 (S1P) and site-2 (S2P) proteases to act as a transcription factor. This proteolytic release of SREBP stimulates lipid synthesis in hepatocytes and other cells (31). Notably, genistein treatment of HepG2 cells was found to decrease the expression of FAS but did not change the expression of SREBP-1 mRNA, likely via the downregulation of S1P expression and subsequent SREBP-1 proteolytic cleavage (32). Thus, whether red clover isoflavones reduce FAS expression by the same pathway remains to be elucidated.

To the best of our knowledge, the present study is the first to demonstrate the antidiabetic effect of red clover extract in type 2 diabetic animals. Red clover extract improves lipid homeostasis in type 2 diabetic animals. In the present study, we demonstrated the PPAR $\alpha / \gamma$ agonist activities in vivo and elucidated the antidiabetic and hypolipidemic mechanism of red clover extract. We also demonstrated that red clover extract suppressed lipogenesis by inhibiting FAS activity. Our data indicate the benefit of a dietary supplement of red clover extract for diabetes patients.

\section{Acknowledgements}

This study was supported by the Science and Technology Planning Project of Fujian Province, China (grant no. 2010N0023) and the Educational Commission of Fujian Province, China (grant no. JA10258).

\section{References}

1. Wong MC, Emery PW, Preedy VR and Wiseman H: Health benefits of isoflavones in functional foods? Proteomic and metabonomic advances. Inflammopharmacology 16: 235-239, 2008.

2. Usui T: Pharmaceutical prospects of phytoestrogens. Endocr J 53: 7-20, 2006.

3. Bhathena SJ and Velasquez MT: Beneficial role of dietary phytoestrogens in obesity and diabetes. Am J Clin Nutr 76: 1191-1201, 2002.

4. Lee JS: Effects of soy protein and genistein on blood glucose, antioxidant enzyme activities, and lipid profile in streptozotocininduced diabetic rats. Life Sci 79: 1578-1584, 2006.

5. Mezei O, Banz WJ, Steger RW, Peluso MR, Winters TA and Shay N: Soy isoflavones exert antidiabetic and hypolipidemic effects through the PPAR pathways in obese Zucker rats and murine RAW 264.7 cells. J Nutr 133: 1238-1243, 2003.

6. Jayagopal V, Albertazzi P, Kilpatrick ES, et al: Beneficial effects of soy phytoestrogen intake in postmenopausal women with type 2 diabetes. Diabetes Care 25: 1709-1714, 2002.

7. Li Z, Hong K, Saltsman P, et al: Long-term efficacy of soy-based meal replacements vs an individualized diet plan in obese type II DM patients: relative effects on weight loss, metabolic parameters, and C-reactive protein. Eur J Clin Nutr 59: 411-418, 2005.

8. Gobert CP, Pipe EA, Capes SE, Darlington GA, Lampe JW and Duncan AM: Soya protein does not affect glycaemic control in adults with type 2 diabetes. Br J Nutr 103: 412-421, 2009.

9. González S, Jayagopal V, Kilpatrick ES, Chapman T and Atkin SL: Effects of isoflavone dietary supplementation on cardiovascular risk factors in type 2 diabetes. Diabetes Care 30: 1871-1873, 2007.

10. Qiu L, Ye H, Chen L, Hong Y, Zhong F and Zhang T: Red clover extract ameliorates dyslipidemia in streptozotocin-induced diabetic C57BL/6 mice by activating hepatic PPAR $\alpha$. Phytother Res 26: 860-864, 2012.

11. Kota BP, Huang TH and Roufogalis BD: An overview on biological mechanisms of PPARs. Pharmacol Res 51: 85-94, 2005.

12. Shen P, Liu MH, Ng TY, Chan YH and Yong EL: Differential effects of isoflavones, from Astragalus membranaceus and Pueraria thomsonii, on the activation of PPARalpha, PPARgamma, and adipocyte differentiation in vitro. J Nutr 136: 899-905, 2006

13. Inoue $\mathrm{M}$, Ohtake $\mathrm{T}$, Motomura $\mathrm{W}$, et al: Increased expression of PPARgamma in high fat diet-induced liver steatosis in mice. Biochem Biophys Res Commun 336: 215-222, 2005.

14. Kim SY, Kim HI, Park SK, et al: Liver glucokinase can be activated by peroxisome proliferator-activated receptor-gamma. Diabetes 53 (Suppl 1): S66-S70, 2004.

15. Mueller M, Hobiger S and Jungbauer A: Red clover extract: a source for substances that activate peroxisome proliferator-activated receptor alpha and ameliorate the cytokine secretion profile of lipopolysaccharide-stimulated macrophages. Menopause 17: 379-387, 2010.

16. Qiu L, Lin B, Lin Z, Lin Y, Lin M and Yang X: Biochanin A ameliorates the cytokine secretion profile of lipopolysaccharidestimulated macrophages by a PPAR $\gamma$-dependent pathway. Mol Med Report 5: 217-222, 2012

17. Guo L and Tabrizchi R: Peroxisome proliferator-activated receptor gamma as a drug target in the pathogenesis of insulin resistance. Pharmacol Ther 111: 145-173, 2006.

18. Ronis MJ, Chen Y, Badeaux J and Badger TM: Dietary soy protein isolate attenuates metabolic syndrome in rats via effects on PPAR, LXR, and SREBP signaling. J Nutr 139: 1431-1438, 2009.

19. Asgary S, Moshtaghian J, Naderi G, et al: Effects of dietary red clover on blood factors and cardiovascular fatty streak formation in hypercholesterolemic rabbits. Phytother Res 21: 768-770, 2007.

20. Geller SE and Studee L: Soy and red clover for mid-life and aging. Climacteric 9: 245-263, 2006.

21. Lukaczer D, Darland G, Tripp M, et al: Clinical effects of a proprietary combination isoflavone nutritional supplement in menopausal women: a pilot trial. Altern Ther Health Med 11: 60-65, 2005 .

22. Schult TM, Ensrud KE, Blackwell T, Ettinger B, Wallace R and Tice JA: Effect of isoflavones on lipids and bone turnover markers in menopausal women. Maturitas 48: 209-218, 2004.

23. Haines C, James A, Sahota D, et al: Comparison between phytoestrogens and estradiol in the prevention of atheroma in ovariectomized cholesterol-fed rabbits. Climacteric 9: 430-436, 2006. 
24. Howes JB, Sullivan D, Lai N, et al: The effects of dietary supplementation with isoflavones from red clover on the lipoprotein profiles of post menopausal women with mild to moderate hypercholesterolaemia. Atherosclerosis 152: 143-147, 2000.

25. Lefebvre P, Chinetti G, Fruchart JC and Staels B: Sorting out the roles of PPAR alpha in energy metabolism and vascular homeostasis. J Clin Invest 116: 571-580, 2006.

26. Auwerx J, Schoonjans K, Fruchart JC and Staels B: Transcriptional control of triglyceride metabolism: fibrates and fatty acids change the expression of the LPL and apo C-III genes by activating the nuclear receptor PPAR. Atherosclerosis 124 (Suppl): S29-S37, 1996.

27. Vu-Dac N, Gervois P, Jakel H, et al: Apolipoprotein A5, a crucial determinant of plasma triglyceride levels, is highly responsive to peroxisome proliferator-activated receptor alpha activators. J Biol Chem 278: 17982-17985, 2003.
28. Qiu L, Wu X, Chau JF, et al: Aldose reductase regulates hepatic peroxisome proliferator-activated receptor alpha phosphorylation and activity to impact lipid homeostasis. J Biol Chem 283: 17175-17183, 2008.

29. Semenkovich CF: Regulation of fatty acid synthase (FAS). Prog Lipid Res 36: 43-53, 1997.

30. Horton JD and Shimomura I: Sterol regulatory element-binding proteins: activators of cholesterol and fatty acid biosynthesis. Curr Opin Lipidol 10: 143-150, 1999.

31. Horton JD, Goldstein JL and Brown MS: SREBPs: activators of the complete program of cholesterol and fatty acid synthesis in the liver. J Clin Invest 109: 1125-1131, 2002.

32. Shin ES, Lee HH, Cho SY, Park HW, Lee SJ and Lee TR Genistein downregulates SREBP-1 regulated gene expression by inhibiting site-1 protease expression in HepG2 cells. J Nutr 137: $1127-1131,2007$ 